\title{
INCIDÊNCIA DE FUNGOS ASSOCIADOS A SEMENTES DE SOJA TRANSGÊNICA VARIEDADE BRS VALIOSA RR
}

\author{
Thatyane Pereira de Sousa'; Ivaneide Oliveira Nascimento²; Claudio Belmino Maia²; Joacir \\ Morais $^{1}$; Gustavo de Andrade Bezerra ${ }^{1}$; José Wilson Tavares Bezerra ${ }^{3}$. \\ 1Discente do Curso de Agronomia, Universidade Estadual do Maranhão, thatyane_@ hotmail.com \\ ${ }^{2}$ Pesquisador(a) do Departamento de Agronomia Universidade Estadual do Maranhão \\ ${ }^{3}$ Analista da Embrapa Escritório de Negócios de Imperatriz
}

\begin{abstract}
RESUMO: A utilização de sementes de boa qualidade sanitária no plantio é um fator de fundamental importância para o estabelecimento da lavoura, uma vez que a sementes pode servir como fonte de inoculo. Com o presente trabalho se objetivou identificar os principais fungos associados às sementes de soja transgênica variedade BRS Valiosa RR. A análise sanitária foi conduzida no Laboratório de Fitopatologia do Centro de Estudos Superiores de Imperatriz da Universidade Estadual do Maranhão, utilizando-se o "blotter test" de acordo com as Regras para analise de Sementes, do Ministério da Agricultura. As sementes foram incubadas em condições de fotoperíodo por sete dias, com incidência de luz branca fluorescente num intervalo de 12 horas de luz e 12 horas de escuro, à temperatura de aproximadamente $26 \pm 5^{\circ} \mathrm{C}$, durante sete dias. Após esse período as sementes foram examinadas individualmente, sob microscópio estereoscópico e óptico e os resultados foram expressos em percentagem de incidência de fungos. Foram identificados cinco gêneros de fungos: Aspergillus flavus, Aspergillus niger, Rizopus sp., Colletotrichum truncatum, Fusarium semitectum, Penicillium sp. Os quais podem afetar o desenvolvimento de plântulas no campo.
\end{abstract}

PALAVRAS-CHAVE: patógenos, sanidade, qualidade.

\section{IMPLICATIONS OF FUNGI ASSOCIATED WITH SEEDS OF SOYBEAN VARIETY BRS VALUABLE RR}

\begin{abstract}
The use of good quality seeds to plant health is a factor of considerable importance for the establishment of the crop, since the seed is directly associated with the transmission of pathogens in culture. The present work is aimed to identify the fungi associated with seeds of transgenic soybean variety BRS Valuable RR. Health Analysis was conducted at the Laboratory of Phytopathology, Centre for Advanced Studies at the University of Imperatriz, Maranhão State, using the "blotter test" in accordance with the Rules for Seed Testing, Ministry of Agriculture. The seeds were incubated in photoperiod for seven days, with an incidence of whitefluorescent light at an interval of 12 hours light and 12 hours of darkness at a temperature of approximately $26 \pm 50 \mathrm{C}$ for seven days. After this period the seedswere examined individually under a stereomicroscope and optical and results were expressed as a percentage incidence of fungi. We identified five genera of fungi: Aspergillus flavus, Aspergillus niger, Rizopus sp., Colletotrichum truncatum, Fusarium emitectum, Penicillium sp. This may affect the development of seedlings in the field.
\end{abstract}

KEY-WORDS: pathogens, quality, sanity.

Agroecossistemas, v. 3, n. 1, p. 52-56, 2011 


\section{INTRODUÇÃO}

A soja Glycine $\max$ (L.) Merrill é o principal componente do agronegócio brasileiro (RIGA et al., 2001). Nas últimas cinco décadas, a soja tem apresentado uma taxa de crescimento superior à taxa de crescimento populacional, ocupando papel fundamental na alimentação humana e animal nos continentes (CARRARO, 2003).

A qualidade da semente é o somatório de todos os atributos genéticos, físicos, fisiológicos e sanitários que afetam a capacidade das sementes de originar plantas de alta produtividade. A qualidade sanitária compreende a condição da semente quanto à presença e grau de incidência de microorganismos e insetos (POPINIGIS, 1985). Contudo, a boa qualidade de sementes produzidas, é um fator de extrema importância para o sucesso da cultura, especialmente nessas novas áreas produtoras (BLACK, 2000).

Dessa forma a semente de soja assume importante papel na disseminação e transmissão de inúmeros microrganismos, sendo os fungos os de maior ocorrência (GOULART, 1991). Os danos causados por microrganismos transmitidos por sementes são bastante variáveis, estando na dependência do patógeno envolvido e do inóculo inicial do mesmo, da espécie cultivada, das condições climáticas vigentes no decorrer do desenvolvimento da cultura
(LUCCA FILHO, 2006). Portanto o teste de sanidade de sementes tem como objetivo determinar a condição sanitária de um lote de sementes, fornecendo informações para programas de certificação, serviços de vigilância vegetal, tratamento de sementes, melhoramento de plantas e outros (HENNING, 1994; MACHADO, 2000). Sendo o objetivo do deste trabalho identificar os fungos associados à sementes de soja transgênica variedade BRS Valiosa RR.

\section{MATERIAL E MÉTODOS}

O trabalho foi conduzido no Laboratório de Fitopatologia do Centro de Estudos Superiores de Imperatriz da Universidade Estadual do Maranhão. A variedade de soja utilizada foi a BRS valiosa RR, oriunda do estado de Goiás.

As sementes de soja foram desinfestadas em solução de Hipoclorito de Sódio $(\mathrm{NaOCl})$ a $1 \%$ de cloro ativo por 3 minutos, seguida de 3 lavagens com água destilada. Posteriormente, as mesmas foram plaqueadas em placas de Petri, previamente esterilizadas, contendo três camadas de papel de filtro umedecido com água destilada. Foram plaqueadas 400 sementes, segundo as regras de análise de sementes pré-estabelecidas (BRASIL, 2009), empregando-se 20 sementes por recipiente.

As sementes foram incubadas em condições de fotoperíodo por sete dias, com 
incidência de luz branca fluorescente num intervalo de 12 horas de luz e 12 horas de escuro, à temperatura de aproximadamente $26 \pm 5{ }^{0} \mathrm{C}$, durante sete dias. Após esse período foram examinadas individualmente, sob microscópio estereoscópico e óptico e os resultados foram expressos em percentagem de incidência de fungos.

\section{RESULTADOS E DISCUSSÃO}

Com a análise sanitária das sementes de soja foram identificados cinco gêneros de fungos Aspergillus sp. 8,53\% (Aspergillus flavus e Aspergillus niger), Rizopus sp. 8,53\%, Colletotrichum truncatum 23,64\%, Fusarium semitectum 25,58\%, Penicillium sp. $33,72 \%$ (Figura 1).

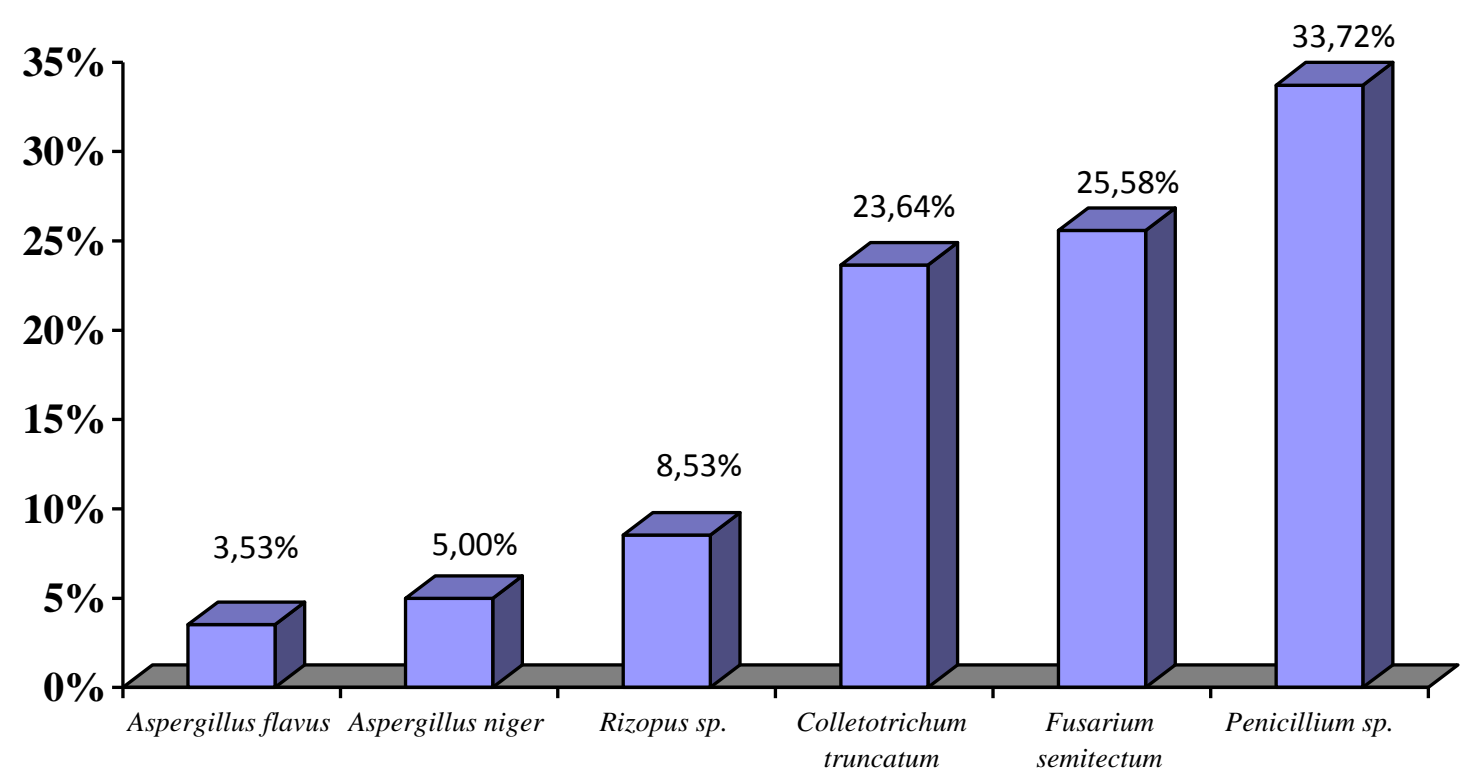

Figura 1: Fungos associados à sementes de soja da Variedade de soja transgênica BRS Valiosa RR.

Dos fungos encontrados dois apresentamse como patógenos à cultura da soja o Colletotrichum truncatum e Fusarium semitectum são classificados por Henning (2005) como patógenos comumente causadores de doenças em soja.

O Colletotrichum truncatum é o fungo causador da antracnose, que é uma das principais doenças da soja. Sob alta umidade causa apodrecimento e queda das vagens, abertura das vagens imaturas e germinação dos grãos em formação (EMBRAPA, 2005).

O Fusarium semitectum, torna-se importante, pois pode causar problemas de germinação em laboratório semelhante ao Phomopsis sp. O fungo está comumente associado às sementes por sofrerem atraso de 
colheita ou deterioração por umidade no campo (HENNING, 2005).

O Rhizopus sp.(8,53\%) apresentou baixa incidência e não está associado a doenças na cultura da soja, Henning (2005) classifica esse gênero fúngico como contaminante e/ou saprófita. Novembre e Marcos-Filho (1991) relatam que apesar de não ter sido totalmente esclarecida, existem preocupações quanto aos possíveis efeitos desse fungo sobre a qualidade das sementes.

Os fungos Penicillium sp., Aspergillus niger e Aspergillus flavus são considerados na literatura como fungos de armazenamento levando as sementes a sua rápida deteriorização quando as condições de armazenagem são inadequadas. O Aspergillus sp., além de ser considerado fungo de armazenamento é responsável pela podridão da semente no solo, quando a semeadura é feita em solos de baixa disponibilidade de água. Para França Neto et al. (2007) diversas espécies de Penicillium e Aspergillus podem infectar qualquer semente, pois esses fungos são capazes de se desenvolver sobre quase todo tipo de matéria orgânica, desde que as condições de temperatura e de umidade relativa do ar ambiente sejam favoráveis.

\section{CONCLUSÕES}

Foram identificados cinco gêneros de fungos: Aspergillus flavus, Aspergillus niger,
Rizopus sp., Colletotrichum truncatum, Fusarium semitectum, Penicillium sp.

\section{REFERÊNCIAS}

BLACK, R. J. Complexo soja: fundamentos, situação atual e perspectivas. In: Escola Superior de Agricultura "Luiz de Queiroz". Soja: Tecnologia de produção. Piracicaba: FEALQ, 2000. p.1-17.

BRASIL. Manual de Análise Sanitária de Sementes. Ministério da Agricultura, Pecuária e Abastecimento. Secretaria de Defesa Agropecuária.Brasília: Mapa/ACS, 2009. 200 p.

CARRARO, I. M. Novos Desafios da Soja Brasileira. Encontro Técnico 7. Cascavel: COODETEC/BAYER CropScience, 2003. $114 \mathrm{p}$.

EMBRAPA. Tecnologias de produção de soja - região central do Brasil, Sistemas de produção 6. Londrina: Embrapa Soja: 2005, 220 p.

FRANÇA NETO, J. B.; KRZYZANOWSKI, F. C.; PÁdUA, G. P. de. Tecnologia da produção de sementes de soja de alta qualidade - Serie sementes. Londrina: EMBRAPA-CNPSo, 2007. 12 p. (EMBRAPA- CNPSo. Circular técnica, 40)

GOULART, A. C. P. Eficiência do tratamento químico de sementes de soja no controle de Colletoptrichum dematiun var. Taumate. 
Revista Brasileira de Sementes, v. 13, n. 1, p.1-8, 1991.

HENNING, A. A. Patologia de Sementes. Londrina: EMBRAPA - CNPSo, 1994. 43p. (EMBRAPA - CNPSo. Documento 90).

HENNING, A. A. Patologia de Sementes: Noções gerais. Londrina: EMBRAPA Soja, 2005. 52p.

LUCCA FILHO, O. A. Patologia de Sementes In: PESKE, S.T.; LUCCA FILHO, O.A.; BARROS, A.C.S.A. Sementes: Fundamentos Científicos e tecnológicos, $2^{a}$ ed., 2006, 473p.

MACHADO, J. da C. Tratamento de sementes no controle de doenças. Lavras: LAPS/UFLA/FAEPE, 2000. 138p.

NOVEMBRE, A. D. L. C.; MARCOSFILHO, J. Tratamento fungicida e conservação de sementes de feijão. Revista Brasileira de Sementes, Brasília, V. 13, n. 2, p. 105-113, 1991.

POPINIGIS, F. Fisiologia da semente. Brasília: AGIPLAN, 1985, 289p.

RIGA, E.; WELACKY, T.; POTTER, J.; ANDERSON, T.; TOPP, E.; TENUTA, A. The impact of plant residues on the soybean cyst nematode, Heterodera glycines. Can. J. Plant Pathol., v. 23, p. 168-173, 2001. 